\title{
TEKNOLOGI INOVASI PENGOLAHAN LIMBAH PLASTIK MENJADI PRODUK UMKM GUNA MENOPANG EKONOMI KELUARGA DALAM MENCERDASKAN KETERAMPILAN MASYARAKAT
}

\author{
Salsabilah Pratami ${ }^{1}$, Lesi Hertati ${ }^{2}$, Lilis Puspitawati ${ }^{3}$, \\ Rilla Gantino ${ }^{4}$, Meifida Ilyas 5 \\ Universitas Indo Global Mandiri Palembang, Indonesia ${ }^{1}$ \\ Universitas Komputer Bandung, Indonesia ${ }^{2}$ \\ Email:hertatilesi@yahoo.com \\ Universitas Esa Unggul Jakarta, Indonesia ${ }^{3}$ \\ Email: $\underline{\text { ilis.puspitawati@email.unikom.ac.id }}$ \\ Universitas Satya Negara Jakarta, Indonesia ${ }^{4}$ \\ Email: rilla.gantino@esaunggul.ac.id \\ Universitas Satyia Negara Jakarta, Indonesia ${ }^{5}$ \\ meifidacantique@yahoo.id
}

\begin{abstract}
Abstrak
Merubah sampah plastik yang tidak berguna menjadi bahan yang unik yang bernilai mahal masalah yang tidak akan habis, kreativitas menciptakan teknologi yang berasal dari limbah plastik yang menghasilkan uang. Limbah selalu berbanding lurus dengan peningkatan populasi manusia dan tumbuhan yang sulit menyerap air yang mengendap didalam tanah. Kerajinan anyam plastik yang merupakan salah satu dari kebudayaan yang dimiliki manusia guna mengembangkan teknologi meghasilkan keuangan untuk menopang ekonomi keluarga dimasa sulit. Di mana waktu itu dipakai untuk memenuhi kebutuhan sandang dan perlengkapan pendukung sehari-hari. Kerajinan anyaman sampah plastik terus berkembang hingga saat ini. Bahkan hasil kerajinan anyaman sampah pastik sudah menjadi sebagai kebutuhan yang tidak dapat dipisahkan dari kehidupan masyarakat. Macam anyaman perajinan anyaman limbah plastik, cara mendapatkan bahan baku sebagian besar mencari sendiri mengeringkan, kemudian merajutnya. Peralatan yang digunakannya pun umumnya masih sederhana seperti pisau pemotong, pisau penipis, pisau, lem dan gunting.
\end{abstract}

Kata Kunci: Teknologi Inovasi, Pengolahan Limbah Plastik, Produk UMKM, Ekonomi Keluarga, Keterampilan Masyarakat.

\section{Abstract}

Turning useless plastic waste into a unique material that is worth an expensive problem, creativity creates technology that comes from plastic waste that generates money. Waste is always directly proportional to the increase in human and plant populations, which find it difficult to absorb water that settles in the soil.Plastic woven crafts are one of the cultures possessed by humans to develop technology to generate finance to support the family economy in difficult times. Where that time is used to meet the needs of clothing and daily support equipment. The craft of woven plastic waste continues to grow today. Even the handicrafts of woven waste have become an inseparable need from people's lives. Kinds of woven plastic waste crafts, the way to get the raw material is mostly to find it yourself, dry it, then knit it. The equipment he uses is generally still simple, such as cutting knives, thinning knives, knives, glue and scissors.

Keywords: Innovation Technology, Plastic Waste Management, MSME Products, Family Economics, Community Skills. 


\section{PENDAHULUAN}

Sampah plastik merupakan sampah yang paling banyak dibuang oleh manusia karena banyak orang yang menggunakan plastik untuk keperluannya sehari-hari entah itu perorangan, toko, maupun perusahaan besar. Misalnya, berbelanja pasti akan membutuhkan plastik untuk membawa barang belanjaan, jika plastik itu sudah tak terpakai apakah plastik itu akan disimpan? Tidak kan. Apa yang mereka lakukan? membuang dan membakar itulah yang mereka lakukan. Pembuangan sampah-sampah plastik kedalam air dan tanah telah menambah tingkat kesengsaraan alam. Mengapa demikian? sampah plastik terbuat dari bahan anorganik. Bahan-bahan anorganik tersebut sangat sulit dan tidak mungkin diuraikan oleh bakteri pengurai, (Paudel, 2018).

Apabila ditimbun dalam tanah untuk menguraikannya butuh waktu berjuta-juta tahun. Dikutip dari jurnal Kerajinan Anyam sebagai Pelestarian Lokal merupakan teknik membuat karya seni rupa yang dilakukan dengan cara menumpang tindikan (menyilangkan) bahan anyam yang berupa lungsu dan pakan. Lungsi adalah bahan anyaman yang menjadi dasar dari media anyam, sedangkan pakan adalah bahan anyaman yang digunakan sebagai media anyaman dengan cara memasukkannya ke dalam bagian lungsi yang sudah siap untuk dianyam. (Pokharel, 2017: Ranjit, 2016). Dan apabila dibakar hanya akan menjadi gumpalan dan butuh waktu lama untuk mengurainya. Dan apakah kalian tahu akibatnya jika sampah plastik itu terlalu lama tertimbun dalam tanah dan tertumpuk?, pertama, terjadi pemanasan global yang berdampak pada kehidupan manusia itu sendiri. Kedua, berdampak pada hewan laut yang menelan sampah plastik yang terbawa ke laut,dan lain-lain. Di negara Indonesia masih bergantung pada plastik lain halnya dengan negara Jepang yang sudah sadar akan bahaya plastik dan beralih pada kertas yang tidak mudah sobek, serta dapat diolah dengan mudah. Pada akhirnya daur ulang sampah plastiklah yang harus kita lakukan.

Tidak hanya menyelamatkan lingkungan dari pemanasan global, tetapi juga dapat mendatangkan keuntungan ekonomi. Semakin meningkatnya sampah maka akan menjadi masalah serius bila tidak dicari penyelesaiannya. Di satu sisi penemuan plastik ini mempunyai dampak positif yang luar biasa, karena plastik memiliki keunggulankeunggulan dibanding material lain. Keunggulan plastik dibanding material lain diantaranya kuat, ringan, fleksibel, tahan karat, tidak mudah pecah, mudah diberi warna, mudah dibentuk, serta isolator panas dan listrik yang baik. Oleh sebab itu, limbah plastik memiliki banyak keunggulan jika dapat dimanfaatkan menjadi produk daur ulang. (Wulandari, Hertati, Antasari, Nazarudin, 2021).

Bisnis daur ulang sampah telah berlangsung sejak lama dan merupakan bisnis besar yang dijalankan secara sistematis. Untuk menjadi pebisnis daur ulang plastik, seorang perlu membangun sistem pengumpulan sampah yang baik, menjalin kerjasama dengan pemulung, memiliki fasilitas pengolahan sampah, serta mengenal pangsa pasar produk daur ulang plastik yang diproduksinya. Meskipun tetap menggunakan plastik 
sebagai bahan baku utama, bisnis kreasi sampah plastik yang penulis tawarkan tidak sekompleks bisnis daur ulang plastik yang bercorak industrial dan bisnis ini dapat dilakukan secara mandiri. Sebagai produk kreatif, karya kreasi sampah plastik memiliki nilai komersial yang menjanjikan. Produk ini memiliki daya jual yang dapat menghasilkan keuntungan bisnis kreasi sampah plastik dapat menjadi salah satu gerakan pemberdayaan komunitas. Hal ini merupakan salah satu kekuatan produk yang dapat dikomunikasikan pada konsumen. Proses produksi yang dilakukan melibatkan banyak pihak, mulai dari warung kopi, penjahit, tenaga administratif, dan lain lain. Menjalankan bisnis sampah plastik berarti menambah lapangan pekerjaan dan membuka kemungkinan peningkatan kesejahteraan masyarakat. (Bapat, Mazumdar, Shih, Bhattacharjee, 2015).

\section{METODE}

Sebagai solusi atas permasalahan yang sedang dihadapi seperti yang telah diuraikan diatas, maka dapat diterapkan beberapa metode kegiatan yaitu:

1) Pemberian pelatihan desain yang inovatif. Pelatihan desain yang inovatif ini adalah bagian sebagian kegiatan yang membuat produk di dalam mendesainnya. Kegiatan desain ini mengambil limbah plastik disekitarnya untuk dijadikan souvenir yaitu berupa tas.

2) Melakukan pengemasan dan branding untuk tas yang telah dihasilkan. Memasang label pada tas yang dihasilkan.

3) Pelatihan pembuatan produk yang baik. Pada pelatihan ini menyamakan persepsi bagi para pengrajin sehingga hasil yang dihasilkan oleh para pengrajin sama.

4) Peningkatan teknologi pembuatan produk. Peningkatan produksi dilakukan karena adanya beberapa alat seperti mesin jahit furing dan alat pelubang. Penambahan sebagian alat-alat dimaksudkan untuk bisa mengejar target penjualan yang lebih banyak.

Daur ulang menjadi salah satu alternatif yang dapat digunakan untuk mengatasi pencemaran lingkungan, karena dengan adanya daur ulang dapat mengurangi jumlah dari banyaknya sampah plastik yang ada dunia. Meskipun sekarang masih belum dapat kita rasakan dampaknya,akan tetapi dimasa yang akan datang daur ulang menjadi tindakan yang tidak bisa dianggap sebelah mata lagi. Disisi lain perlu adanya TPS ${ }_{3} \mathrm{R}$ di setiap lingkungan untuk memilih dan memilah sampah. Dengan begitu akan lebih mudah menanggulangi permasalahan sampah plastik, (Archak, et,all,2011).

Pada umumnya sampah atau botol plastik yang sudah tidak lagi berguna akan dibiarkan begitu saja atau dibakar. Apabila dibakar dalam skala yang besar maka dapat menimbulkan polusi udara pada lingkungan sekitar. Namun polusi tersebut dapat diatasi dengan cara memisahkan sampah organik dan anorganik kemudian diolah untuk dilakukan daur ulang. Perlu adanya sosialisasi dari pemerintah setempat mengenai dampak bahaya dari pembakaran sampah sehingga mengakibatkan polusi 
udara. Perlu penyediaan tempat sampah dan daur ulang sampah yang disediakan pemerintah setempat. (Akamani, \& Hall, 2015: Gantino, Hertati, Ilyas, 2021).

Sampah-sampah yang berserakan dimana-mana dan tumpukan sampah dapat menyebabkan sumber penyakit. Tentunya akan sulit untuk mengolah sampah dengan jumlah yang sangat banyak tersebut. Akan tetapi apabila kita bisa berkontribusi dalam pengolahan dan daur ulang sampah,maka secara tidak langsung kita berperan aktif dalam mencegah timbulnya penyakit. Salah satu cara yang dapat dilakukan yaitu dengan membuat tong yang berbeda untuk memisahkan jenis sampah yang bermacammacam agar dapat dilakukan daur ulang botol bekas, dan barang bekas lainnya.

\section{HASIL DAN PEMBAHASAN}

\section{Tahapan Pelaksanaan Kegiatan}
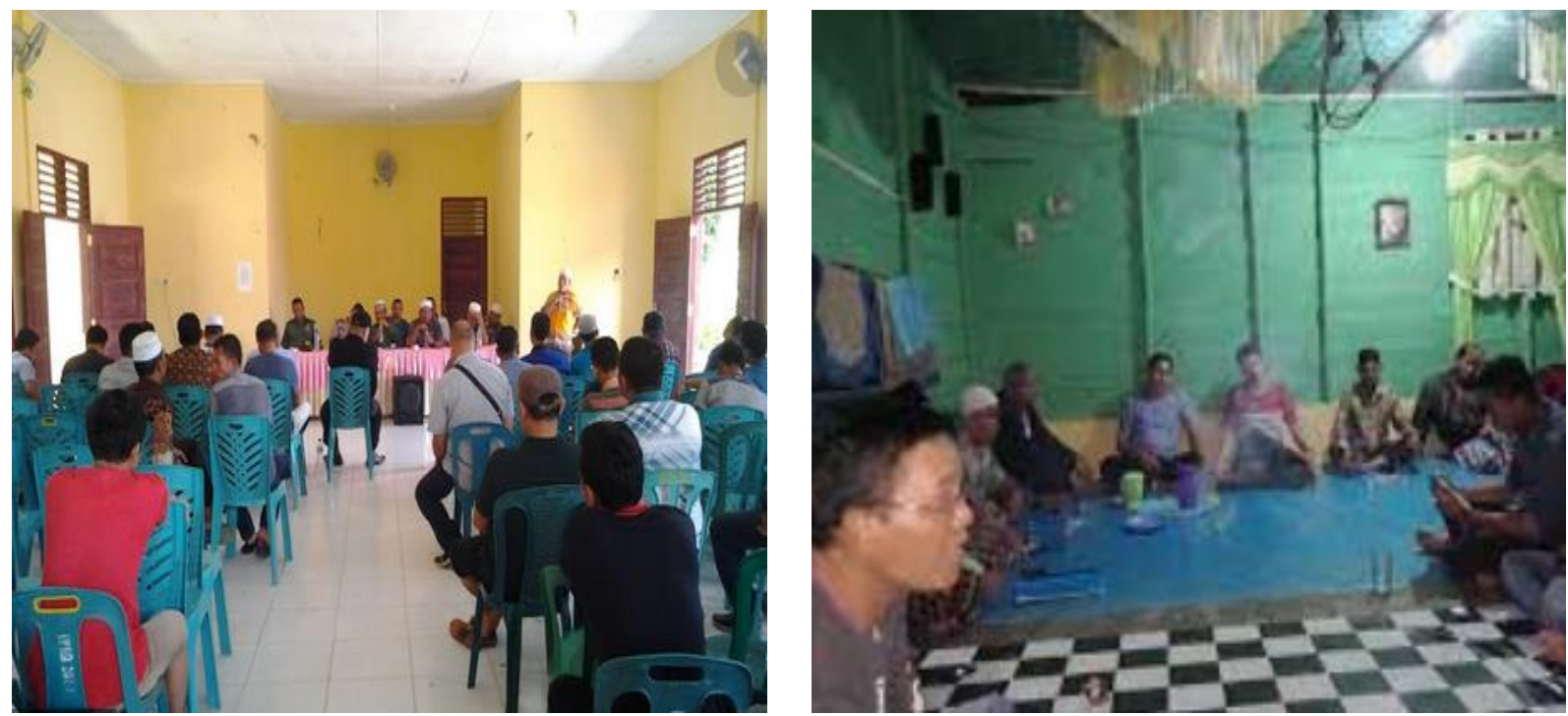

Gambar 1. Pelatihan Keterampilan Merangkai Limbah Plastik, 2021
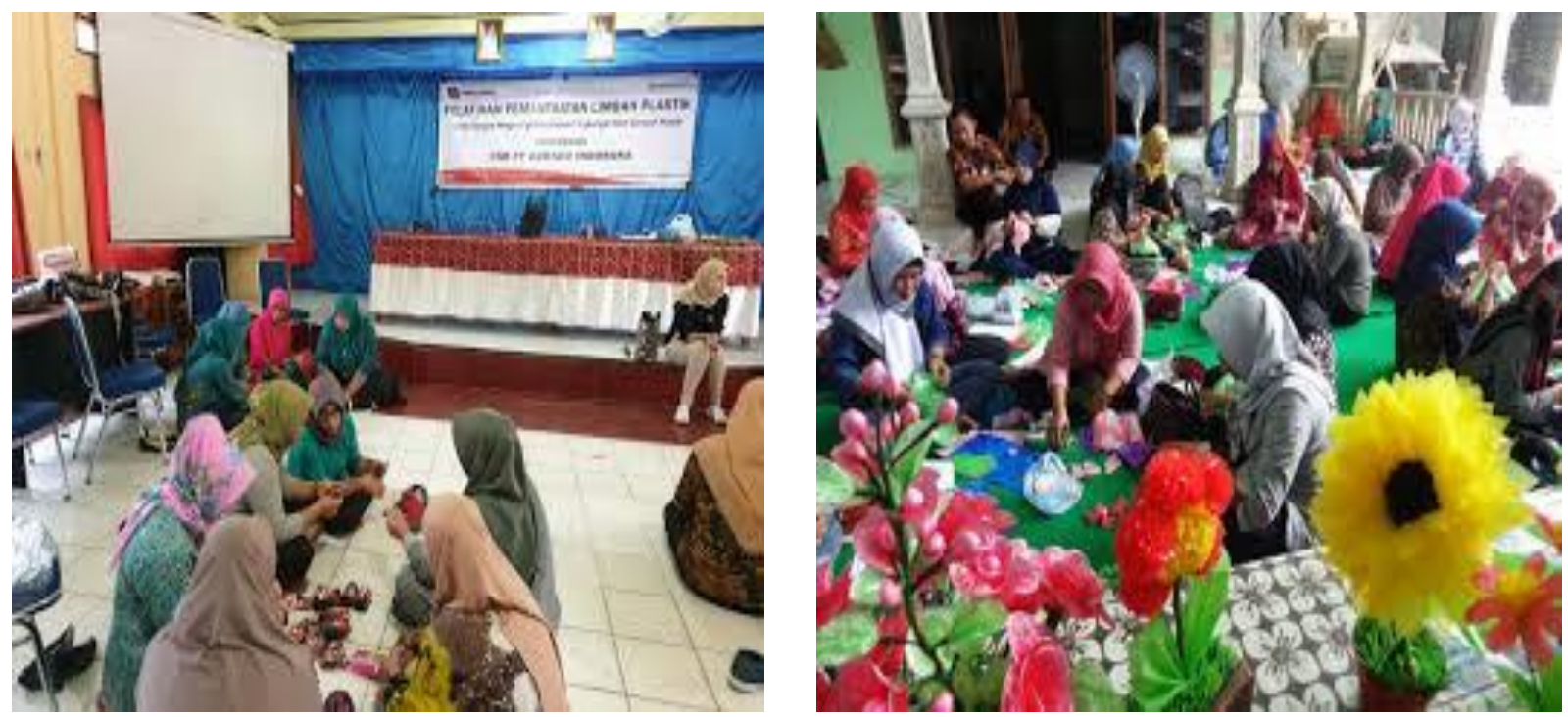

Gambar 2. Kegiatan Pemanfaatan Limbah Plastik, 2021 


\section{Proses Pembuatan Limbah Plastik}

\section{Membuat Tas dari Limbah Plastik Bekas}

\section{○ Alat dan bahan :}

1. Plastik bekas kemasan deterjen cair (rinso, so klin liquid, dan lain-lain) atau minuman bubuk (marimas, pop ice, dan lain-lain).

2. Gunting.

3. Bahan hiasan dapat berupa renda, kain flannel, resleting, sesuai keinginan.

\section{- Cara membuat :}

1. Siapkan plastik bekas kemasan cukup banyak.

2. Bersihkan plastik plastik tersebut hingga bersih dari sisa-sisa deterjen yang tertinggal didalam kemasan.
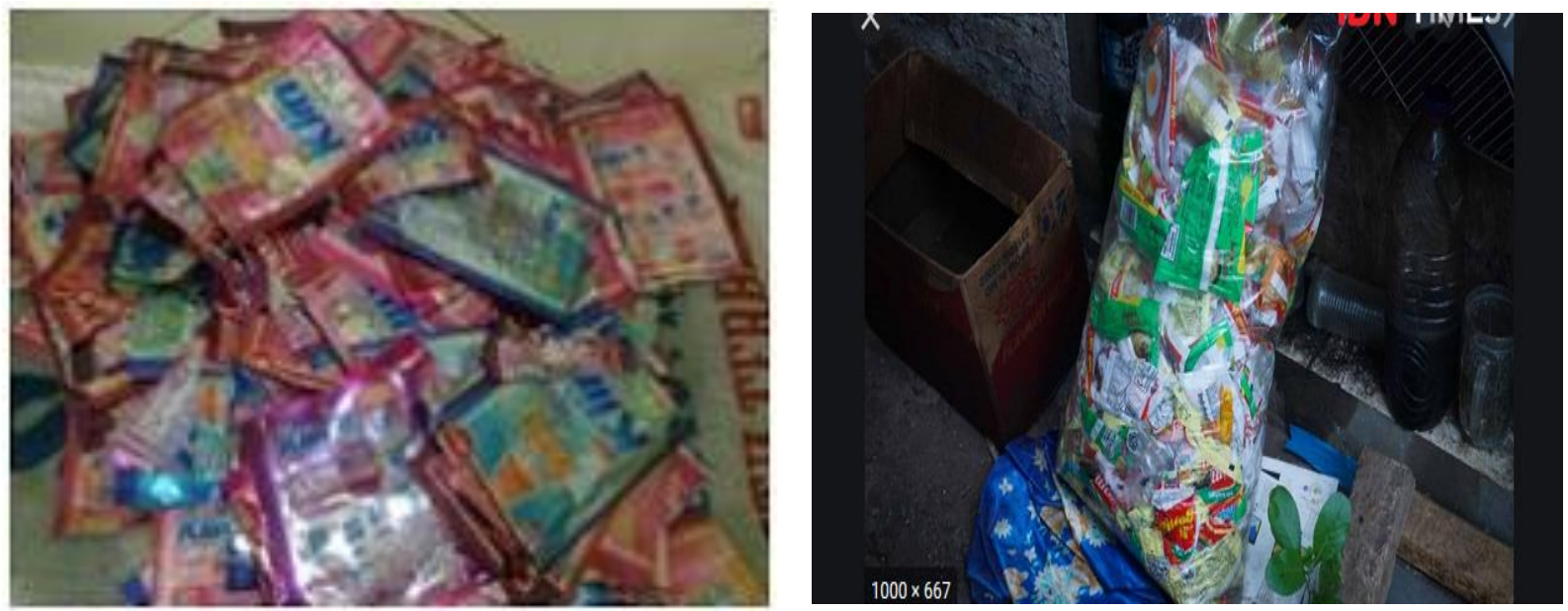

Gambar 3. Kegiatan Pemanfaatan Limbah Plastik, 2021

3. Kemudian potong dengan gunting setiap plastik kemasan tersebut menjadi tiga bagian seperti pada gambar.

4. Kemudian keringkan boleh dengan di jemur dibawah sinar matahari ataupun diangin-anginkan saja.

5. Setelah kering, ambil satu bagian kemudian lipat menghadap ke dalam kemasaan menjadi seperti pada gambar.

6. Setelah semua terlipat, rangkaikan satu per satu hasil lipatan menjadi anyaman berbentuk segi tiga atau ketupat.

7. Cara membuat anyaman adalah ambil 2 buah plastik yang sudah dilipat kemudian masukkan salah satu lipatan ke bagian tengah lipatan lainnya, kemudian ambil lagi sebuah lipatan plastik lainnya selipkan pada salah satu ujung lipatan yang sudah dirangkai lebih dahulu, ambil lagi sebuah lipatan plastik masukkan kesalah satu lipatan. Prinsip dari pengerjaan anyaman ini adalah anyaman dengan motif satu-satu. Jadi jika satu bagian plastik masuk lipatan maka yang satu lipatan lagi harus dikeluarkan hingga terbentuk seperti gambar diatas.

8. Setelah terbentuk satu rangkaian anyaman, lanjutkan rangkaian hingga membentuk memanjang sesuai selera yang akan digunakan sebagai dasar tas. 
9. Lakukan langkah membuat anyaman berulang hingga menjadi bentuk tas.

10. Tahap terakhir adalah memasang kelengkapan tas seperti tali dan berbagai hiasan seperti rendah.
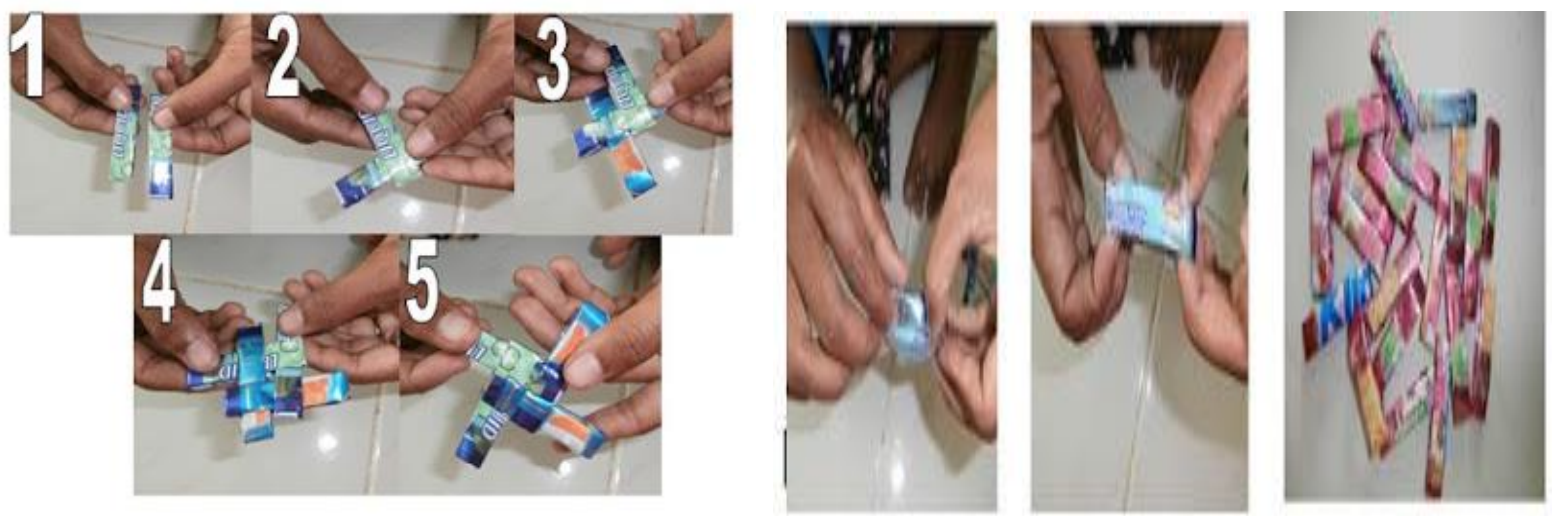

Gambar 4. Kegiatan Penganyaman Limbah Plastik, 2021
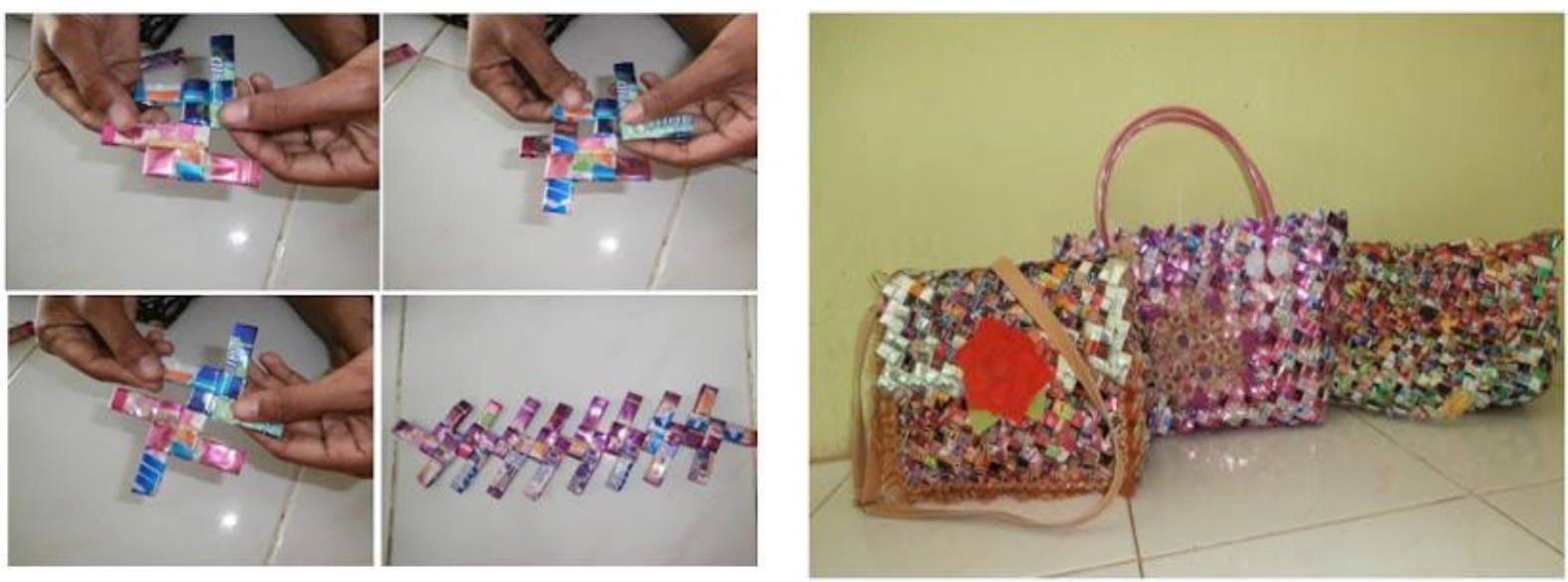

Gambar 5. Kegiatan Hasil Penganyaman Limbah Plastik, 2021

Bukan hanya tas yang bisa dibuat untuk pemanfaatan limbah plastik tetap bisa juga menjadi banyak barang yang dapat dihasilkan berikut beberapa kerajinannya :
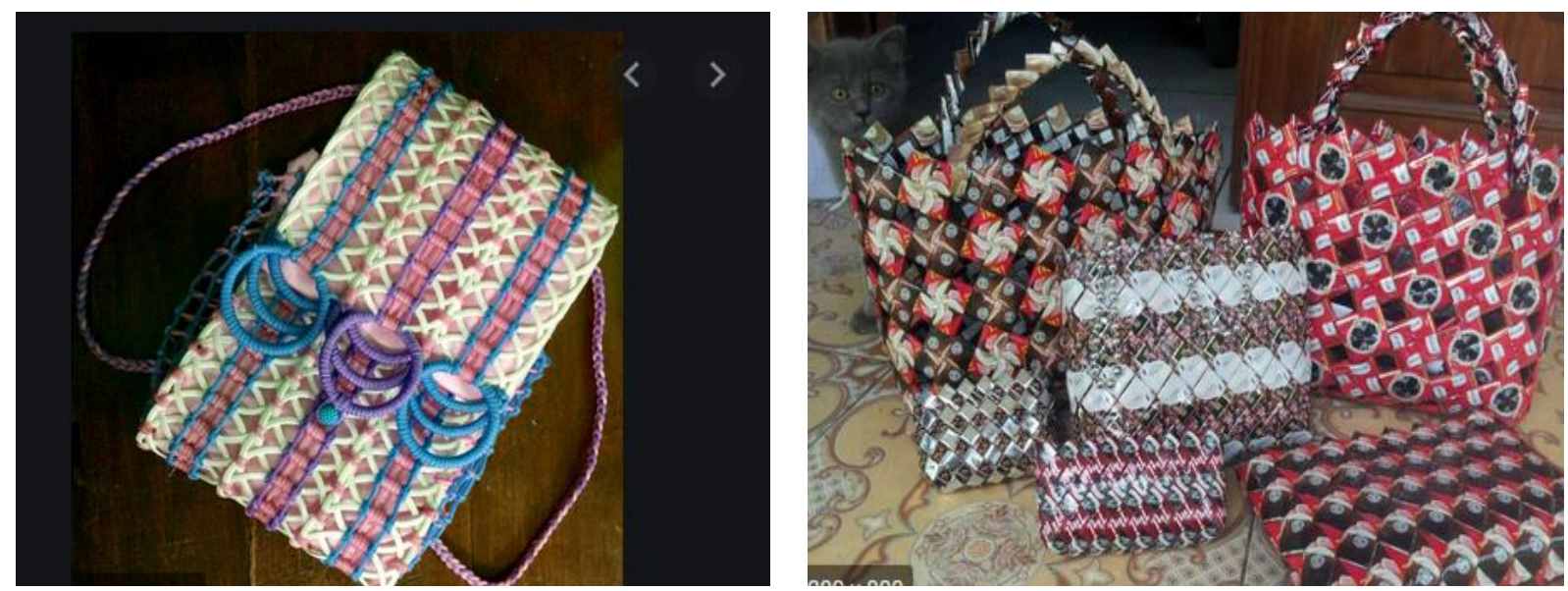

Gambar 6. Kegiatan hasil penganyaman Limbah Plastik, 2021 

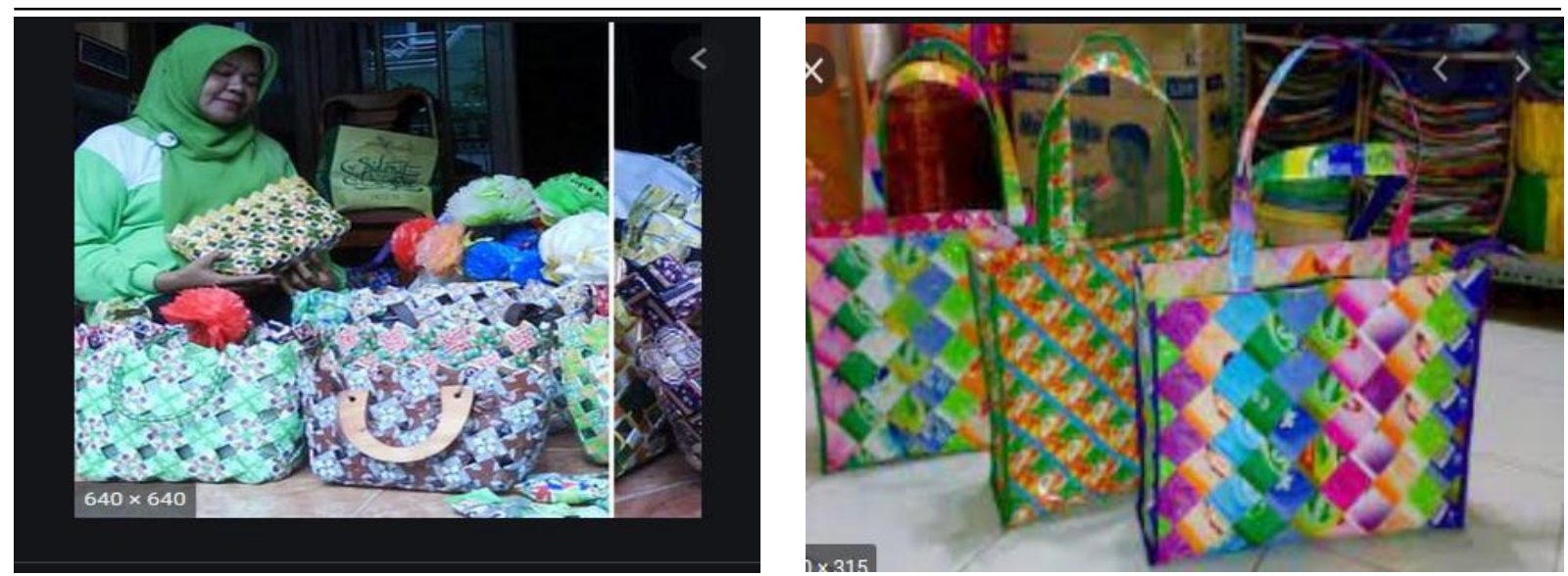

Gambar 7. Kegiatan Hasil Penganyaman Limbah Plastik, 2021
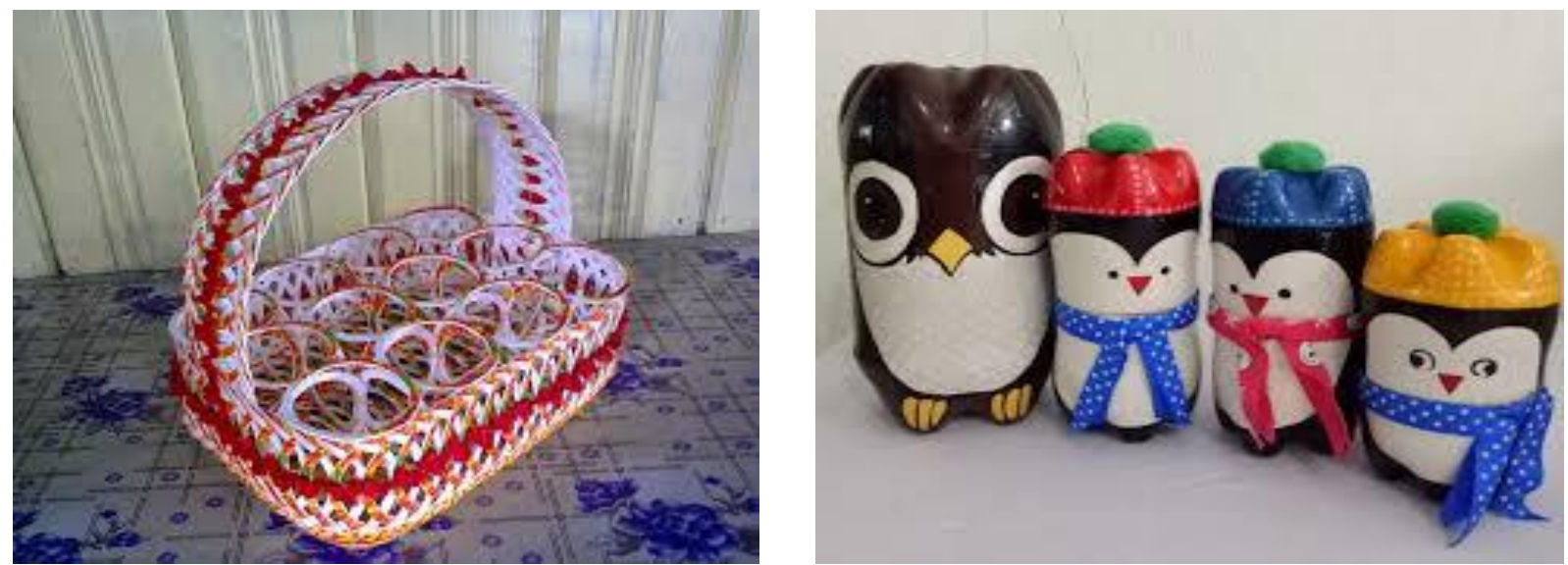

Gambar 8. Kegiatan Hasil Penganyaman Limbah Plastik, 2021
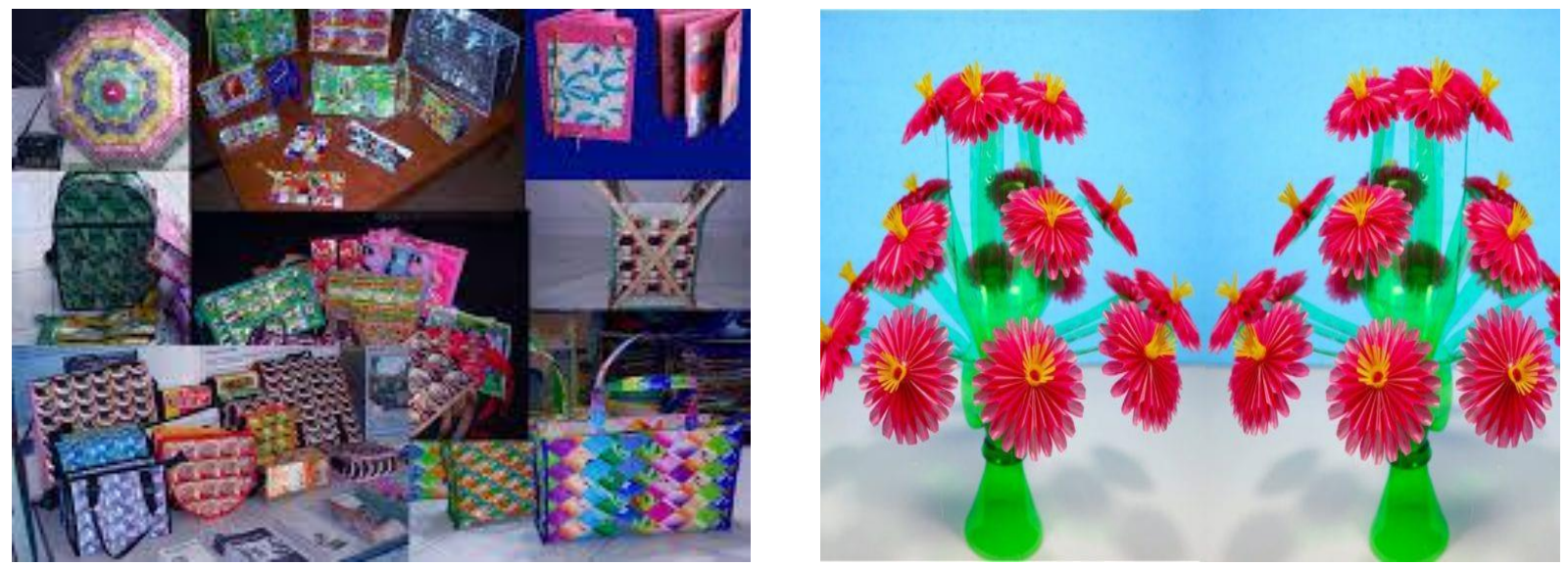

Gambar 9. Kegiatan Hasil Penganyaman Limbah Plastik, 2021

\section{Faktor Pendukung dan Faktor Penghambat}

Sampah rumah tangga yang sebagian besar merupakan bahan plastik botol mineral dan minyak bumi, atau dari proses industri. Beberapa dari bahan ini tidak terdapat di alam seperti plastik dan aluminium. Sebagian zat anorganik secara keseluruhan tidak dapat diuraikan oleh alam, sedang sebagian lainnya hanya dapat diuraikan melalui proses yang cukup lama,( Aaker,2013). Sampah jenis ini misalnya 
berupa botol kaca, botol plastik, tas plastik, kaleng,dan barang rumah tangga lainnya. jumlah produksi sampah plastik global sejak 1950 hingga 2015 cenderung selalu menunjukkan peningkatan. Pada 1950, produksi sampah dunia ada di angka 2 juta ton per tahun. Sementara 65 tahun setelah itu, pada 2015 produksi sampah sudah ada di angka 381 juta ton per tahun. Angka ini meningkat lebih dari 190 kali lipat, dengan ratarata peningkatan sebesar 5,8 ton per tahun.

Sampah plastik di dunia terus meningkat setiap tahun seiring dengan kebutuhan masyarakat dalam penggunaan plastik. Sampah-sampah plastik ini menjadi salah satu masalah terbesar yang dialami oleh berbagai negara di dunia karena sifatnya yang sulit terurai namun keberadaanya terus meningkat. Oleh karena itu diperlukan tindakan preventif agar jumlah dari sampah plastik dapat dikurangi,serta perlu adanya tindakan pengolahan sampah plastik yang tidak berguna menjadi barang yang bermanfaat bagi lingkungan sekitar.Salah satu cara yang dapat mengurangi keberadaan sampah plastik yaitu dengan cara daur ulang plastic, (Camacho, et, all, 2015: Fadhilia, Liwa, Shemdoe, 2016: Hertati, Asmawati,Widiyanti, 2021).

\section{Faktor Pendukung}

Kegiatan Pengabdian pada masyarakat ini telah terlaksana dengan baik berkat dukungan berbagai faktor yaitu:

a. Komunikasi dan Koordinasi Tim

Komunikasi antar anggota tim berlangsung lancar dan efektif sehingga koordinasi tim pada proses persiapan, pembagian tugas, dan pelatihan dapat berlangsung dengan baik dan tepat waktu. Hal ini juga didukung kompetensi tim pengabdi khususnya tim instrukur dalam bidang yang diajarkan memadai sehingga tidak ada permasalahan yang mempersulit jalannya pelatihan karena semua permasalahan terkait dengan materi dapat terselesaikan sehingga peserta pelatihan benar-benar terbimbing dengan baik.

b. Komitmen Peserta Pelatihan

Peserta pelatihan yang terdiri dari Ibu-Ibu Rumah Tangga sangat antusias dan bersemangat dalam mengikuti pelatihan dari awal hingga akhir. Begitu pula saat penugasan dimana perserta tersebut diminta untuk membuat sendiri karya seni limbah sampah plastik, mereka sangat bersemangat untuk bekerja dan menanyakan segala sesuatu terkait hal yang mereka kerjakan.

c. Penerimaan yang Baik dari Masyarakat

Animo peserta sangat besar dan mendukung kegiatan serta menyambut baik, serta berharap dapat dilibatkan lagi dalam pelatihan-pelatihan yang akan datang dan peserta menharapakan kegiatan ini bisa di lanjutkan dimasa yang akan dating dengan menawarkan failitas tempat untuk pelaksanaan pelatihan.

\section{Faktor Penghambat}

Keterbatasan waktu juga sangat terkait dengan keterbatasan biaya, akan tetapi jumlah tatap muka dirasa cukup memadai sehingga pelatihan ini menjadi lebih bermakna dan bermanfaat dalam memberikan pemahaman dan keterampilan bagi 
peserta. Antusiasme peserta menjadikan mereka merasa waktu pelatihan terlalu singkat karena harus berakhir di saat peserta telah mulai memahami materi dan praktik Akan tetapi hampir semua peserta berhasil menyelesaikan karya seni keterampilan dari limbah sampah plastik.

\section{KESIMPULAN}

Simpulan yang dapat diperoleh dari pelaksanaan program pengabdian kepada masyarakat pengaruh teknologi inovasi pengolahan limbah plastik menjadi produk UMKM guna menopang ekonomi keluarga dalam mencerdaskan keterampilan masyarakat didorong oleh partisipasi yang tinggi dari mitra program pengabdian kepada masyarakat memberikan dampak positif bagi pelaksanaan program, terlihat dari pelatihan dan pendampingan dalam pembuatan produk. Pelaksanaan program mampu menghasilkan produk produk yang memiliki nilai jual yang tinggi. Bahwa sampah plastik dapat menguntungkan, jika kita memiliki kreativitas dalam mengolah sampah plastik sebaiknya kembangkan, tidak hanya mendatangkan keuntungan kita juga telah menyelamatkan dunia. Menganyam merupakan salah satu kerajinan tangan yang masih banyak dilakukan oleh masyarakat di pedesaan. Pembuatan seni anyam dalam masyarakat Indonesia merupakan kegiatan turun temurun. Mereka membuat berbagai hiasan anyaman seperti hiasang dinding, alat dapur, tikar, atau dinding dari anyaman bambu yang kemudian dijual. Anyaman adalah hasil menganyam, barang yang sudah dianyam. Pada mulanya kegiatan menganyam dan menyulam dilakukan untuk memenuhi kebutuhan peralatan rumah tangga seperti tikar, bakul, sarung atau selendang, dimana dengan menggunakan bahan bahan limbah plastik. Dalam perkembangannya, anyaman dan tenunan sebagai produk karya seni rupa semakin beragam sejalan dengan perkembangan bahan dan teknik yang digunakan. Saat ini anyaman tidak hanya berbahan alami, tapi juga berbahan sintesis. Produknya beranekaragam pula, dari benda-benda yang tergolong seni terapan hingga seni murni. Oleh karena itu, disarankan agar pengolahan sampah harus mengikutin mode perkembangan teknologi informasi agar barang hasil anyaman laris dipasaran disamping itu juga pembersihan lingkungan di Desa karena dampak dari lingkungan kotor dapat mendatangkan penyakit bagi kita sendiri dan masyarakat sekitarnya. Untuk itu mulai sekarang marilah kita melakukan pola hidup sehat dan tidak membuang sampah sembarangan. Dan mulai peduli terhadap kehidupan bersama agar dapat menciptakan kesejahteraan dalam bermasyarakat serta mau untuk terus meningkatkan keterampilan agar dapat meningkatkan ekonomi masyarakat bersama. 


\section{REFERENSI}

Aaker, D., A. Et al. (2013) Marketing Research: 11th International Student Version. LA.Jon Wiley.

Alam, I., \& Management, J. (2012). Innovation Strategy, Process and Performance in The Commercial Banking Industry Innovation Strategy, Process and Performance in The Commercial Banking Industry, 37-41.

Andersen, B. Henriksen., B, Aarseth., W.W. (2006). Holistic Performance Management: an Integrated Framework", International Journal of Productivity and Performance Management, 55 (1), 61-78.

Aral, S., dan Dellarocas., C. (2011). Introduction to the Special Issue-Social Media and Business Transformation: A Framework for Research Information System Research, 24 (1), 3-13.

Archak, N, Ghose, A., \& Ipeirotis, P. G. (2011). Deriving the Pricing Power of Product Features by Mining Consumer Reviews. Management Science, 57 (8), 1485-1509.

Arjomandi, A., Harvie, C., \& Valadkhani, A. (2012). "An Empirical Analysis of Iran's Banking Performance", Studies in Economics and Finance, 29 (4), 287-300.

Akamani, K., Hall, T.E., (2015). Determinants of the Process and Outcomes of Household Participation in Collaborative Forest Management in Ghana: a Quantitative Test of Acommunity Resilience Model. J. Environ. Manag, 147, 1-11.

Bapat, D., Mazumdar, D, Shih, T. T., Bhattacharjee. (2015) "Assessment of Business Strategy: Implication for Indian Banks". Journal of Strategy and Management, 8 Iss 4, 306-32.

Barney, J.B. (2010). Gaining and Sustaining Competitive Advantage, Fourth Edition. Addison. Wesley, Massachusetts.

Best, Roger J. (2013). Market-Based Management (6 th Edition), Strategies for Growing Customer Value and Profitability. NY.Pearson Higher Education.

Camacho, L.D., Gevana, D.T., Carandang, A.P., Camacho, S.C. (2015). Indigenou Sknowledge and Practices for Sustainable Management of Ifugao Forests in Cordillera, Philippines. Inter. J. Biodiv. Sci. Ecosys. Serv. Mgt, 12, 5-13.

Fadhilia, B., Liwa, E., Shemdoe, R. (2016). Indigenous Knowledge ff Zigi Community Andforest Management Decision-Making: a Perspective of Community Forest Interaction. J. Nat. Res. Dev, 6, 14-22.

Gantino.R, Hertati .L. Ilyas.M. (2021). Taxpayer Compliance Model Moderated by Socialization Taxation SMEs.

Hertati.L, Zarkasy.W, Adam.M., Umar.H, Suharman.H. (2020). Decrease in Labor Levels in the Covid-19 Government Budget. Ilomata International Journal of Tax \& Accounting, 1 (4), 193-209.

Hertati, L.Safkaur.O. (2020). Dampak Revolusi Industri 4.o Era Covid-19 pada Sistem Informasi Akuntansi Terhadap Struktur Modal Perusahaan. Jurnal Riset Akuntansi dan keuangan, 8 (3), 503-518. 
Hertati, L.Asmawati, Widiyanti. M. (2021). Peran Sistem Informasi Manajemen di Dalam Mengendalikan Operasional Badan Usaha Milik Daerah. Insight Management Journal, 1 (2), 55-67.

Hertati.L Feri.I,Puspitawati.L Gantino.R, Ilyas.M.(2021). Pengembangan UMKM Unggulan Gambomuba Produk Lokal Guna Menopang Perekonomian Rakyat Akibat COVID-19. Indonesia Berdaya, 2(1), 55-68.

Obineche, J.O., (2017). Kola Nut: Revisiting the Igbo Socio-Cultural Values and Identity. Inter. J. Arts Hum, 6, 94-1.

Paudel, J., (2018). Community-Managed Forests, Household Fuelwood Use and Foodconsumption. Ecol. Econ, 147, 62-73.

Pokharel, R.K., (2017). Indigenous Forest Management Practices in Some Community Forestsof Nepal. Banko Janakari, 10, 37-39.

Ranjit, Y. (2016). Determinants of People's Participation in Forest Protection Andmanagement: a Study in Kaski, Nepal. Econ. J. Dev, Iss. 17, 175-186.

Wulandari.W, Hertati.L, Antasari.R, Nazarudin. (2021). The Influence of the Covid-19 Crisis Transformative Leadership Style on Job Satisfaction Implications on Company Performance. Ilomata International Journal of Tax \& Accounting (IJTC), 2,(1), 17-36. 